\title{
Non-Institutional Factors Affecting Microentrepreneurship Development in Bangladesh
}

\author{
Md. Mahmudul Alam* \\ PhD Student \\ Institute for Environment and Development (LESTARI) \\ National University of Malaysia (UKM) \\ E-mail: rony000@gmail.com \\ Mohammad Muntasir Hossain \\ Director \\ Personal Social Responsibility Initiative (PSRi) \\ Dhaka, Bangladesh \\ Farhana Zaman \\ Accounts Analysis Assistant \\ Finance Cluster, UNDP \\ Dhaka, Bangladesh \\ ${ }^{*}$ Corresponding author
}

\section{Citation Reference:}

Alam, M.M., Hossain, M.M., and Zaman, F. 2011. Non-institutional Factors Affecting Microentrepreneurship Development in Bangladesh, International Review of Business Research Papers, Vol. 7(6): 240-247. Available at < http://www.bizresearchpapers.com/16.\%20Mahmudul.pdf >

This is a pre-publication copy.

The published article is copyrighted by the publisher of the journal. 


\title{
Non-Institutional Factors Affecting Microentrepreneurship Development in Bangladesh
}

\begin{abstract}
The magnitude of microentrepreneurial activities plays a decisive role in the economic development of the rural livelihoods, especially in third world countries. Microentrepreneurship has always been considered as a proven instrument to fight poverty in an effective manner. As a consequence, poverty alleviation through rural centric microentrepreneurship development has been focused for more than the last thirty five years in Bangladesh. However, despite such initiatives, the state of microentrepreneurship in Bangladesh has not yet reached to a satisfactory level. There are a number of prevailing factors that thwart the development of microentrepreneurship in Bangladesh. Among all the factors, non-institutions encompassing various political, economic, social, cultural, technological, environmental and personal factors are affecting the scopes of operating these economic activities to a significant extent. This paper attempts to identify the key non-institutional barriers that hinder the development of microentrepreneurship in Bangladesh, and suggests a composite policy measure to overcome such encumbrances.
\end{abstract}

Field of Research: Development Economics; Microcredit; Microenterprise; Microentrepreneur; Microentrepreneurship

JEL Codes: O12, O15, O43

\section{Introduction}

Microentrepreneurs as informal sector enterprises that usually possess the following features- ease of entry, family ownership, small-scale operation, reliance on indigenous resources, use of labor intensive and adopted (often low-level) technology, acquisition of skills outside the formal schooling system, and unregulated and competitive market prevalence (ILO 1972).

In Bangladesh, microentrepreneurship is often associated with cottage industries and sometimes referred as the informal sectors or petty traders that chiefly involved in livestock, agriculture, fisheries, cottage, food processing sectors, trading and small manufacturing businesses. According to Credit and Development Forum (CDF), businesses with less than 10 thousands Taka capital investment can be considered as petty trades where microenterprises are those which require more than 10 thousands up to 1 million Taka (Alam and Miyagi, 2004).

Entrepreneurship has been always regarded as a major contributing factor to the economic growth, especially small and microenterprises have a substantial impact in developing countries. McPherson (1996) said that development programs aimed to promote microentrepreneurship have been a popular poverty alleviation strategy in developing nations for many years, starting as early as 1947. Different observations also suggest that the rural development of the poorest countries happened largely as a result of the economic activity and intensity of insignificant entrepreneurs- called microentrepreneurs, and the 
financial support of associations for such entrepreneurs are commonly called microcredit associations (Bornstein, 2005).

The role of microentrepreneurship development has received acute focus in Bangladesh because of its multidimensional contribution to socioeconomic development. From the very beginning of the post liberation stage after 1971, microentrepreneurial initiatives emerged in Bangladesh as a spontaneous reflex of the poor to cope with the disastrous economic situation of that time. Starting with 71 percent population living below the poverty line in 1973-1974, the reduction of poverty has always been the highest priority of the government of Bangladesh. In the reality of having a large population, numerous low skilled workers, and soaring unemployment trend, the government's major development objective was always to create sustainable employment platform to generate income and eventually lessen poverty. In doing so, poverty alleviation through rural centric microentrepreneurship development has been focused for more than the last thirty five years in Bangladesh.

In Bangladesh, previous development and poverty reduction initiatives were primarily built on national Five Year Plans where poverty reduction was at the forefront. After discontinuing these Five Year Plans, Bangladesh initiated PRSP, now again back to the Five Year Plans, with objectives to reduce poverty and eventually to achieve the relevant Millennium Development Goals. With this in view, both government and NGOs put their combined efforts for the development of microcredit programs and microentrepreneurship in Bangladesh. Along with the government, $688 \mathrm{MFIs}, 2$ government departments, 6 specialized organizations, and 7 commercial banks (PKSF, 2006) are working towards fostering microentrepreneurship development, in direct or indirect ways. It is believed that over 7000 NGOs now run microcredit programs in Bangladesh and after adjustment for overlapping, the borrowers account to nearly 24.5 million (Ahmad, 2010). At the same time, internationally reputed rural development models like the Comilla, BRAC, ASA, and Grameen models, originated and developed in Bangladesh, are also in function for the development of microentrepreneurship in Bangladesh. However, despite such initiatives, the state of microentrepreneurship in Bangladesh has not yet reached to a satisfactory level.

According to the Household Income and Expenditure Survey (2005), during the last decade, Bangladesh registered a modest poverty reduction rate of 1 percent per year from 50.1 percent in 1995 to 40 percent in 2005. However, latest CPD (2008) analyses reveal that, an additional 8.5 percent people have fallen below the poverty line in recent times because of high inflation. Consequent erosion of purchasing power ultimately has initiated drastic reversal of poverty alleviation trends achieved so far. Moreover, it is quite evident from recent findings that, there is a highly vulnerable group of people who stand marginally above the poverty line. At this point, prudent microentrepreneurship development not only can neutralize the adverse effect on poverty reduction, but also at the same time carry on the poverty reduction level to the desired extent. 
Existing literature identified very few factors that hinder the development of microentrepreneurship. According to a model by Pisani and Patrick (2002), microentrepreneurs suffer from poor efficiency and low productivity because of their poor quality and unreliable supplies, outdated machineries, unskilled personnel, small sizes, and limited access in monetary supports from financial institutions, government and non-government agencies. McElwee (2006) also explored the situation that is being faced by microentrepreneurs and found that they go through significant difficulties in accessing capital, distribution channels, and relevant business supports.

Researchers across the globe differ from one another in defining the factors that affect the overall development process of microentrepreneurship. Traditional models and institutional supports are not able to overcome a number of prevailing factors that thwart the development of microentrepreneurship in Bangladesh. This paper attempts to identify the noninstitutional key barriers that hinder the development of microentrepreneurship in Bangladesh. The next section describes several types of non-institutional barriers and the recommendation for formation of a specialist agency to overcome the problems, and conclusion.

\section{Non-Institutional Barriers}

A broad range of controllable and uncontrollable non-institutional components such as political, social, cultural, technological, natural, and personal factors shape up the overall development process of microentrepreneurship and it sustainability in long run (Alam et al. 2010).

Local economic factors such as - size of the local market and its demand generated by local purchasing power influence the entrepreneurs' business decisions. Businesses also depend on the geographical characteristics that lead towards specific business types historically. A crucial factor of production labor and its availability and price (wage rate) are also considered as crucial factors in developing any entrepreneurship practice and type of business concentrations. High rate of wages influences microentrepreneurs inclined to selling labor and at the same time hiring labor for microenterprises becomes more costly - both the scenarios work as barriers for the micro businesses. Local standard of living alters the characteristics of the microentrepreneurships, in cases of superior living standards; people are most likely to prefer SME over microenterprise to receive relevant services.

The geographical position also defines microentrepreneurship businesses, such as, microenterprises mostly run in the remote villages. Moreover, the quality of land plays an immense role for the success of agricultural businesses. The sustainability of microenterprises also depends heavily on availability of supplies, raw materials, price volatility of relevant goods, and price inflation of the product, substitute goods, demand elasticity of the goods and so on.

The economy of Bangladesh is hugely affected by the frequent natural catastrophes like flood, cyclone, and drought. The natural consequences of 
these natural calamities followed by virulent diseases weaken the production and also cause to livestock sickness. During monsoon period, Bangladesh goes through the longest rainy season in the world. 20-25 percent of Bangladesh's land is flooded by rain almost every year. Heavy floods have occurred every after two or three years and wiped out about 70-80 percent of the total land damaging crops, houses, bridges, and even human lives over the last 30 years. This is one of the major reasons that pull the standard of living in the country down tremendously along with the rise of mass-poverty, unemployment, malnutrition, crisis, epidemic, etc. Flood is a recurrent crisis in Bangladesh. These calamities gravely damage the course of micro businesses. Ensuring immunity from the adverse effect of climate change will be a major concern in upcoming days to sustain microentrepreneurship growth.

In literature, it is an undisputed fact, that culture holds a deep impact on all aspects of entrepreneurial initiatives in societies (Hayton, George and Zahra, 2002). Generally, the word culture refers to the complex of meanings, symbols, and assumptions to differentiate between superior and evil as well as rightful and unlawful that lies beneath the prevailing practices and values of a particular society (Bourdieu, 1972; Markus and Kitayama, 1994). Local cultures, values and norms and their application facilitates entrepreneurship to a large scale. In Bangladesh, microentrepreneurs are also influenced by the local norms, customs, mores, traditions, and also religion. More generally, the level of culture consists of formal legal rules and regulations, encompassing constitutions, law, property rights, governance structures etc.

Local governance sets environment which impacts the growth of entrepreneurial movements. Different community based laws, such as tribal laws, affect the development of microenterprises. Different communities of people as broadly categorized through demographic position, regional cohesiveness or cultural orientation mutually agree upon doing small business practices based on community acceptance and formal laws and informal regulations.

Religious beliefs, interpretation and implementation often dictate the progress. The culture of a society can also be influenced by high level of corruption, low level of education and awareness of the citizens of the society, as these factors shape up an individual's perception of moral and social responsibilities. In Bangladesh, factors like depravity, low level of security, theft and robbery, fragile regulatory environment and lack of consciousness has influenced its culture which also eventually has influenced values, beliefs and behaviors of individuals. Locality based cultural and demographic factors, such as, ethnic rules, social structure, literacy rate, income level, gender, age group etc define the local demand and profitability. For example, the product that is being produced in a tribe, now only meets the tribal demand. This very demand can be boosted through introducing and promoting the product in other parts of the country.

New technologies bring a robust shift in business approaches. Whenever a new technology arrives, the challenges for microentrepreneurs amplify. It increases the vulnerability of local businesses as it reduces cost of competitors 
as well as increase capital investment requirements for the local microentrepreneurs. The activities of microentrepreneurs are indigenous with traditional production methods and equipments, where new technologies and automated machines are important to adopt to face the challenges of competitors and to improve the quality and stretch the production. The utilization of computer, internet, telephone or mobile services provide a superior edge to the microentrepreneurs. Market information equips small scale businesspeople to get a comprehensive understanding on current market prices, demand-supply scenario and other relevant insights. As there is no thorough and updated market information system, micro-entrepreneurs fail to explore new opportunities, effective technologies, attractive markets, and relevant scopes for their businesses.

A common attribute of microentrepreneurs in Bangladesh is that most of them are forced to become self employed as they had no option left to ensure their survivals rather than being typical entrepreneurs driven by challenge, inheritance, and independence. Most of these people are poor, with little or no education and without any protection of labor law and social security (Malik and Abed, 2007). Another important feature is their small size and their limited linkage with local markets only. They do not have any brand capital or national exposure; rather have an awfully low public visibility. In many cases, microentrepreneurs in Bangladesh are seen to be isolated and disconnected from their respective communities. They are greatly detached from all sorts of local, social and political practices and forced to concentrate narrowly on their own business activities. This can be explained by their inferior public status, inadequate education and limited access to facilities that make them feel deserted. There are other prevailing personal factors such as, personal disability due to accident, aging, bigger family sizes, daily family look after, and pregnancy rest etc. that worsen the situation more.

Individual capacity development is a key priority area for the sustainable growth of these small scale entrepreneurs. Capacity development programs such as trainings on business start-up plans, regular operations, and enterprise developments are long overdue. Disseminating marketing knowledge to equip entrepreneurs with necessary skills to promote their ventures and other professional education such as management, sales, accounting, and strategies will be quite useful to enhance the capacity as a whole. Effective training on various managerial as well as social aspects will contribute largely in enhancing economic independence, self confidence, awareness, decision making process, sense of achievement, social interaction, leadership quality, personal and social capabilities. Fortunately, most of the microentrepreneurs engaged in informal activities do not require extensive training or skills. A few fundamental concepts and approaches will be enough to facilitate them to conduct their businesses smoothly.

\section{Necessity of Formation of a Specialist Agency}

In an integrated approach covering related workgroups from NGOs, MFIs, government, donor agencies, local elite groups and others, a specialist agency or department can be established to provide right advice and assistance to 
microentrepreneurs at the local level. In order to bring microcredit sector under regulatory framework, the government of Bangladesh enacted Microcredit Regulatory Authority Act- 2006, and formed a body of Microcredit Regulatory Authority (MRA). This authority body can perform the role of mentioned agency, but in this case the scopes and Act needs to be changed to a large extend.

The proposed agency will work for capacity building of the microentrepreneurs through offering educational courses and training, just like mass education system, on initial startup plans, marketing approaches, business expansion strategies, problem solving skills, record maintenance of transaction etc. This agency will be responsible to evaluate business plans, monitor the progress and provide necessary advices in various phases. It will also provide guidelines to a microenterprise to grow and transform into a SME, this approach will drive the microentrepreneurs to envision themselves in long run and they will participate with fullest enthusiasm to attain that objective.

This agency will also monitor the local markets and determines the potential sectors where it can further expand existing micro business initiatives. There are many sectors to be explored; already are defined in various literature, such as, organic vegetables production, growing flowers, oilseeds and seed production, mushroom production, bee-keeping, drying out of fruits and vegetables, packaging of pickles, chutneys (a special type of jam), jams, squashes, dairy and other food products which are ready to eat. In agricultural sector there are few new fruits- new types of plum- Bowcul, Applecul, Strawberry, Tang etc has been developed for mass production in Bangladesh. Entrepreneurs can utilize both their technical skills and raw resources from the farm and livestock in the production of Livestock feed and vermi-compost using the animal waste to generate income. They can be widely benefited through establishing small scale agro-processing units. However, it is a continuous process to explore different potential sectors where microenterprises have enough potentiality to grow. The agency will persistently look for new scopes of business activities, run pilot studies, and most importantly, encourage new entrepreneurs with necessary supports. It will also help to bring diversity the microentrepreneurs' portfolio and focus on an export oriented approach which will definitely broaden the horizon for these small scale businesses.

This agency will take the initiatives to form an association of microentrepreneurs to maintain sufficient production level and to take the opportunity of economy of scale in production, and to overcome the shortage of research and development initiatives to enhance their effectiveness and technological efficiency. It will help to adopt training and capacity building programs at the community level to introduce and familiarize the technological implication among microentrepreneurs. It will also provide enough networking support to get updated market information, large scale marketing exposure and exploration of the market.

Government should formulate a national microentrepreneurs protection fund though its specialized agency which will be sponsored by donation from the government, a certain share from the revenues of MFIs and NGOs, aid collected from corporate social responsibility acts, regular charities, religious 
charities (such as, Zakah- religious charity) and donation from international bodies. This protection policy will help the microentrepreneurs recover the uncertain losses, for an example, for reviving after a climate change disaster. This will also facilitate microentrepreneurs to overcome the debt cycle.

Focus should be made on the capacity building of local microcredit retailers and the marketing of the new microcredit products. The agency will establish the codes and standards of operation for the microcredit lenders and provide an extensive microentrepreneurship loan policy by aligning the MFIs, NGOs, government and donor agencies in funding microentrepreneurs. It will provide new modalities of loan financial arrangements on the basis of profit and loss sharing where both risk and effort will be shared, and loan-loss guarantees, defined as a certain percentage of the loan, and flexible financing and installment schedule based on types of business activities etc.

Finally, this agency will work to neutralize the existing non-institutional pressures by addressing the natural, legal, social, political and cultural issues that obstruct the development course. It will counsel and train the local elite groups and run several awareness campaigns to soften their reservation against woman microentrepreneurs and entrepreneurs as a whole. Through sharing ideas, organizing workshops, seminars and award programs involving media it will promote a healthy business environment for the microentrepreneurs.

\section{Conclusion}

In order to reduce the poverty level through accelerating the growth of microentrepreneurship in Bangladesh, the government, policy makers, donors, NGOs, MFls and other relevant organizations need to consider and address non-institutional barriers properly. The integrated approaches are important to overcome the non-institutional barriers through awareness creation, motivational program, sound business plans and a combined external support. Through the right support from the institutional as well as non-institutional associations, microentrepreneurs can strengthen their own capacities besides contributing in both family and national earnings. Since microentrepreneurial movements and capacity building are imperative for economic and social development in Bangladesh in the long run, an integrated approach is necessary to be deployed within shortest possible time.

\section{References}

Ahmad, MM 2010, 'Microfinance in Poverty Reduction in Bangladesh: Challenges and Opportunities', Paper presented at the International Conference on Financial Cooperative Approaches to Local Development through Sustainable Innovation, University of Trento, June 10-11, Italy.

Alam, CM \& Miyagi, K 2004, 'An approachable analysis of micro enterprises in Bangladesh', Working Paper Series 2004-8, The University of Kitakyushu, Japan. 
Alam, MM, Molla, RI \& Hossain, MM 2010, Microentrepreneurship Development in Bangladesh: Achievements and Shortcomings, LAP Lambert Academic Publishing, Saarbrucken, Germany.

Bornstein, D 2005, The price of a dream: The story of the Grameen Bank, Oxford University Press, New York.

Bourdieu, P 1972, Outline of a theory of practice. R. Nice (English Translation 1977), Cambridge University Press, England.

CPD 2008, State of the Bangladesh economy in FY2007-08 and some early signals regarding FY2008-09 (first reading), Centre for Policy Dialogue (CPD), Dhaka, October.

Hayton, J, George, G, \& Zahra, S 2002, 'National culture and entrepreneurship: A review of behavioral research', Entrepreneurship Theory and Practice, vol. 26, no. 4, pp. 33- 52.

Household Income and Expenditure Survey 2005, Statistics Bangladesh 2006, Bangladesh Bureau of Statistics.

ILO 1972. Employment, incomes and equality: A strategy for increasing productive employment in Kenya, International Labour Office, Geneva.

Malik, S \& Abed, FH 2007, Legal mechanisms to empower informal businessBangladesh perspective, Work in progress, UNDP.

Markus, HR \& Kitayama, S 1994, 'A collective fear of the collective: Implications for selves and theories of selves', Personality and Social Psychology Bulletin, vol. 20, no. 5, pp. 568- 579.

McElwee, G 2006, 'Farmers as entrepreneurs: Developing competitive skills', Journal of Developmental Entrepreneurship, vol. 11, no. 3, pp. 187- 206.

McPherson, MA 1996, 'Growth of micro and small enterprises in southern Africa', Journal of Development Economics, vol. 48, no.2, pp. 253-277.

Pisani, MJ \& Patrick, JM 2002, 'Radical political regimes in the Americas and MNC responses: A conceptual model', Latin American Business Review, vol. 3, no.2, pp. 17- 42 .

PKSF (Palli Karma-Sahayak Foundation) 2006, Maps on Microcredit Coverage in Upazilas of Bangladesh, PKSF, Dhaka.

This is a pre-publication copy.

The published article is copyrighted by the publisher of the journal. 